\title{
Estimation of a structural labour supply model for Belgium: application to the earnings test for pension recipients
}

Marjan Maes

HUB RESEARCH PAPERS 2012/41

ECONOMICS \& MANAGEMENT

NOVEMBER 2012
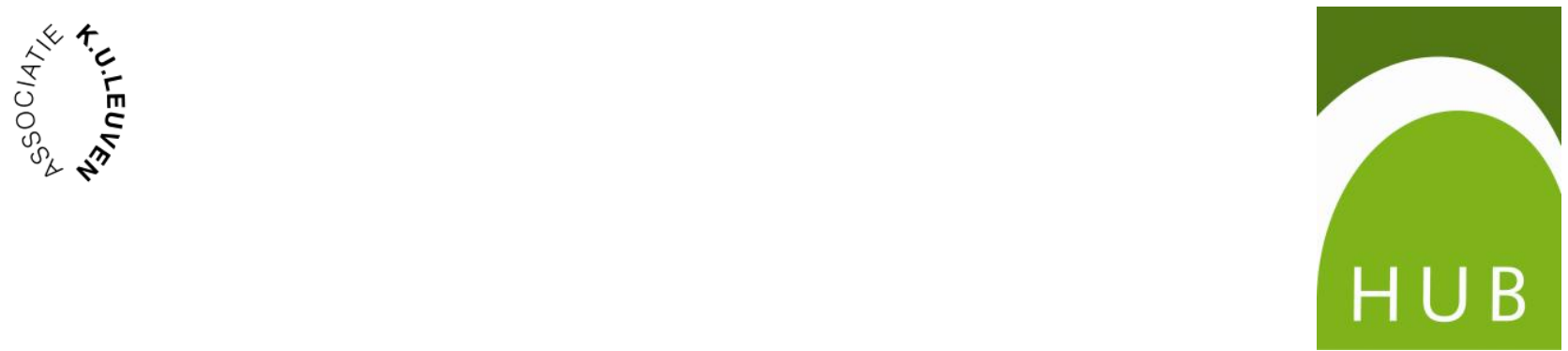


\title{
Estimation of a structural labour supply model for Belgium: application to the earnings test for pension recipients
}

\author{
MarjanMaes ${ }^{1}$
}

\begin{abstract}
In Belgium working pension beneficiaries are subject to a $100 \%$ tax on their pension benefit if their labour income exceeds a certain threshold. The pension is even fully withheld if the threshold is exceeded by more than 15\%. This earnings test is typically perceived as a powerful tax on work by many Belgian citizens. A few years ago the Belgian government increased the threshold for working beneficiaries over 65 providing us with a natural experiment. On the basis of longitudinal administrative data, we estimate a structural labour supply model for employees eligible for pension benefits. It accounts for a piecewise-linear budget constraint (with a convex and a non-convex kink) and heterogenous preferences. We found significant income and wage elasticities The estimates are used for policy simulations. A complete removal of the earnings test over age 65(=normal retirement age) would increase median hours of work per week with 2.9 as a majority in this age category faces a positive substitution effect that outweighs the income effect that affects only a minority of workers. However, a removal of the threshold over age 60(=age of eligibility) would decrease median hours of work from 40 to 25,95 as most individuals in this age category experience a negative income effect while few workers in this age category face a positive substitution effect. The budgetary impact for the government is also considered: it depends on revenues from social contributions and expenditures on pension benefits.
\end{abstract}

The aim of this paper is to estimate a structural labour supply model and to provide labour supply elasticities for workers who are close to retirement. Identification of income and substitution effects is enhanced as our data cover a natural experiment, i.c. a reform which increased the earnings test threshold for working pensioners above 65 in Belgium. This earnings test taxes away pension benefits in case a working pension beneficiary has earnings that cross a certain threshold. It is typically perceived as a powerful tax on work by many Belgian citizens.

The plan of this paper is as follows. A first section discusses theoretical predictions and empirical findings in the literature concerning the impact of earnings test reforms (section 1). The second section presents our sample of longitudinal (1999-2009) administrative micro-data (section 2). Descriptive evidence gives us a feel of the extent of bunching below the earnings test threshold before and after the reform (section 3). This is followed by a difference-indifference analysis to assess the causal impact of the earnings test threshold increase on hours of work. Finally we present estimation results of a structural labour supply model allowing us to disentangle income and substitution effects (section 5). The estimates of this structural model are used for policy simulations, i.e. a complete removal of the earnings test (section 6).

\section{The earnings test: theoretical predictions and empirical findings in the literature}

\footnotetext{
${ }^{1}$ The author gratefully acknowledges financial support from NETSPAR Research grant and the University of Tilburg (CENTER). The author is extremely grateful to Professor Arthur Van Soest for his comments and suggestions.
} 
Notwithstanding the common perceptions that the earnings test should be eliminated for giving strong work disincentives, the international literature, both theoretical models and empirical applications, shows that the earnings test and its removal have an ambiguous impact on aggregate labour supply. To understand this ambiguity, we look at figure $1^{2}$ that displays the piecewise-linear budget constraint of an individual eligible for pension benefits. The horizontal axis shows annual hours of work and the vertical axis total net income that may result from earnings (=wage times hours of work) and/or non-labour income (pension benefits, capital income). In Belgium a pension beneficiary can cumulate pension benefits with earnings up to a certain threshold. The level of the threshold depends on the presence of children at charge and age (before/after age 65) and increased considerably for those above 65, as shown in table 1

\begin{tabular}{|c|c|c|c|c|}
\hline \multicolumn{5}{|c|}{ Table 1: Evolution earnings test thresholds (nominal amounts, in euros) in Belgium for employees } \\
\hline & \multicolumn{2}{|c|}{ Below age 65} & \multicolumn{2}{|c|}{ above age 65} \\
\hline & With child & No child & With child & No child \\
\hline 1999 & \multirow[t]{3}{*}{10286} & \multirow[t]{3}{*}{6857} & \multirow{3}{*}{10286} & \multirow[t]{3}{*}{6857} \\
\hline 2000 & & & & \\
\hline 2001 & & & & \\
\hline 2002 & \multirow{8}{*}{11132} & \multirow{8}{*}{7421} & \multirow[t]{2}{*}{14556} & \multirow[t]{2}{*}{10845} \\
\hline 2003 & & & & \\
\hline 2004 & & & \multirow[t]{2}{*}{17267} & \multirow[t]{2}{*}{13556} \\
\hline 2005 & & & & \\
\hline 2006 & & & 19300 & 15590 \\
\hline 2007 & & & 20860 & 17149 \\
\hline 2008 & & & \multirow[t]{2}{*}{26075} & \multirow{2}{*}{21436} \\
\hline 2009 & & & & \\
\hline
\end{tabular}

For earnings above that threshold, corresponding to a number of hours $\mathrm{h}^{*}$, pension benefits are taxed at $\tau=100 \%$. For earnings above $115 \%$ of the threshold, corresponding to hours of work $\mathrm{h}^{* *}$, pension benefits are even completely suspended. So the earnings test generates a piecewise linear budget constraint that consists of three segments corresponding to earnings below to the threshold, a horizontal segment and earnings above the threshold. Graphically speaking, the wage $W(1-\tau)$ represents the slopes of the segments while virtual non-labour income (Yv) represents the intercepts corresponding to each extended or linearized segment. Under the hypothesis of normally behaved preferences, we expect workers to bunch just below the threshold (corresponding to a convex kink). We also expect that no individuals are located in the non-convex kink $\mathrm{h}^{* *}$. We will show below that that is indeed the case. Suppose now that the threshold increases (to the dashed threshold). On the one hand, those with earnings below the earnings test threshold would experience no incentive to change labour supply. For those with earnings bunching just below the threshold and on the horizontal segment $\mathrm{h}^{*}$-h**, increasing the threshold is equivalent to a reduced tax on their labour income. Because their after tax wage increases, the substitution effect will stimulate them to increase their number of hours worked. On the other hand, for those with earnings above the threshold, to the left of $\mathrm{h}^{* *}$, given their amount of hours worked, an increased threshold yields an increase in net income. If leisure is a

\footnotetext{
${ }^{2}$ This figure supposes we are in a one-period framework which does not allow us to incorporate impact of actuarial adjustment of benefits in case of deferral on the labour supply decision. In addition it supposes that individuals can decide freely the number of hours of work they desire while in practice employees may be forced to choose between a limited range of hours, like part-time or full-time.
} 
normal good, they can afford themselves to supply less hours of work while earning the same income as before. The aggregate labour supply effect depends hence on the relative strength of the income (measured by virtual income) and substitution (measured by wage) effects and on the distribution of individuals within these segments. According to this theory, the impact of the earnings test on labour supply is hence inconclusive.

A similar conclusion is reached from the empirical literature. According to BurtlessMoffit(1985) the removal of the earnings test in the US would raise postretirement hours of work by 3.2-4.4 hours a week. This small aggregate effect is due to the fact that this removal would only affect $12 \%$ of retirees: those bunching at the kink and those above the threshold. According to Honig-Reimers(1989) it would lead to a 13-20\%increase in hours worked for those bunching below the threshold and a 1\% decrease for those above the threshold. According to Friedberg(2000), the removal of the earnings test is expected to increase hours worked for those bunching at the kink with $5.3 \%$, while doubling the threshold ${ }^{3}$ would instead decrease it with $0.2 \%$. The intuition behind this is that an increase, instead of a removal, of the threshold makes the earnings test bind for a new group of high earners who experience not only a negative income effect but also a negative substitution effect. Still, as only $1.3 \%$ of the population aged 63-69 and 4.1\% of workers are bunching, the aggregate employment impact is again negligible. Haider-Louchran(2008) find that $2.2 \%$ of the population aged $62-69$ or $4.8 \%$ of the workers are bunching in the US. The removal of the earnings test above 65 in 2000 increased average hours worked per week with 1.55. According to estimates of Song-Manchester(2007) it increased work participation above 65 with $0.8-2 \%$ points. They argued that this small effect is also due to the simultaneous gradual increase of the NRA from 65 to 67 in the US which makes the earnings test more stringent again for those younger than the NRA. Instead, for the UK, DisneySmith(2002) and Disney-Tanner(2000) showed that a removal of the UK earnings test above 65 led to a considerable $20 \%$ increase of full-time workers coming from part-time work, corresponding to an increase of average weekly hours worked of 65+ workers with 3-4 for men and 2 for women. They attribute this large effect to the fact that in the UK adjustment of pension benefits is actuarially fair in case of deferral and this explains why removing the earnings test has less effect on the fulltime workers who are deferring their claiming decision. In the UK, the decision to defer is not automatic, it is an explicit decision taken by the worker. So basically they did not find evidence of a negative income effect. These results sharply contrast with another study for the UK of Zabalza et al.(1980) who estimated an increase of annual hours of work of barely 10.24 on average for men in case the earnings test were eliminated, via a switch from part-time to full-time work. Note that the predictive power of the structural labour supply model of Zabalza et al.(1980) is however weak while the difference-in-difference model of Disney-Smith(2002) seems to identify more precise effects. Finally for Canada, where actuarial adjustment of benefits is absent above the age of 65, Benjamin-Baker(1999) estimate that the removal of the test above 65 resulted in a small increase of number of weeks worked with 5-6 on average of those still working, i.e. a switch from part-year to full-year work.

Of all these studies, Burtless-Moffit(1985), Friedberg(2000) and Zabalza et al.(1980) estimate a structural labour supply model while the most common approach is to estimate difference-indifference models. While the latter have the advantage to identify causal reform effects if adequate control and treatment groups are available, the former has the advantage that it can

\footnotetext{
${ }^{3}$ Increase from $\$ 14500$ in 1998 to $\$ 30000$ in 2002.
} 
disentangle income and substitution effects on labour supply. Structural models however impose stronger assumptions f.e. on the shape of the utility function. Below we will both estimate a difference-in-difference and a structural model of labour supply.

The situation in Belgium is extremely well-suited to address our research question for at least two reasons. First of all, the considerable increase in the earnings threshold (see table 1) provides us with a "natural experiment" that, with longitudinal micro-data, facilitates the identification of labour supply elasticities. Secondly, in contrast to the UK and US pension scheme, the Belgian old-age benefit scheme does not compensate individuals in the event of deferred claiming past the age of 65 by increasing their future benefit streams. This would, as is the case for all studies based on US and UK data, complicate the identification of labour supply elasticities. Surprisingly, the existing empirical literature is limited to studies on data from Canada, the US and the UK. So far no research projects have been undertaken to measure the possible impact of the removal of the earnings test on labour supply in Belgium.

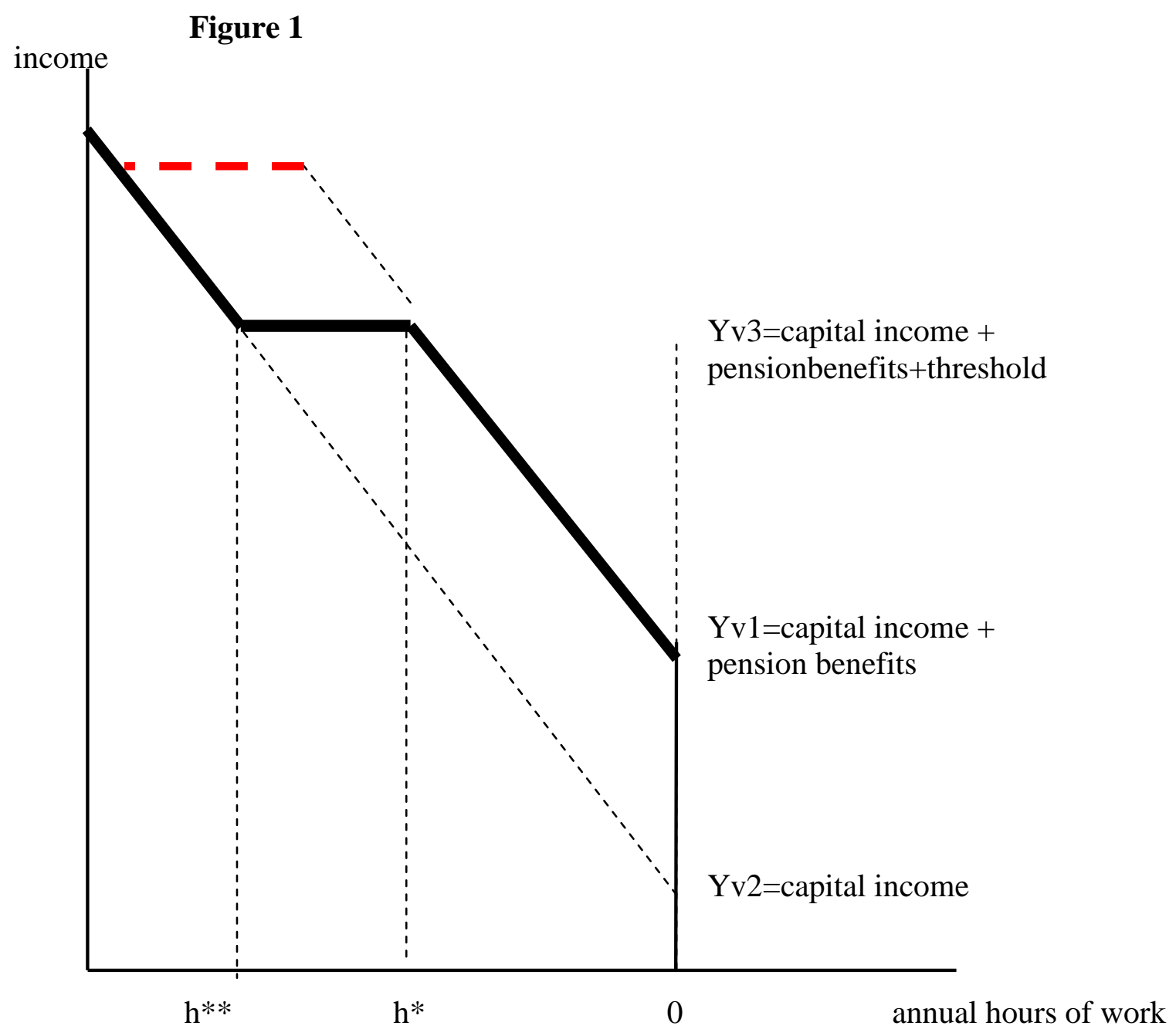

\section{Description of the sample}


We select from the Belgian National Register 80.000 national identification numbers of Belgian men between 57 and 72 years old on 31-12-2003 ${ }^{4}$. These numbers are matched for the years 1999-2009 with variables registered by the different social security institutions to generate a longitudinal panel with the following variables: year and month of birth, year of death, age of other household members, number of children at charge, marital status, region(Flanders, Wallonia, Brussels), NACE-code, replacement income (early retirement(=ER), unemployment $=(\mathrm{UN})$, disability, old-age $(=\mathrm{OA}), .$.$) , earnings, earnings of the spouse, means-tested benefits,$ white/blue collar, professional code (like agriculture, banking-insurance, dentist, ...), official wage class, full/part-time contract $(0-45 \%, 46-55 \%, 56-95 \%$, >95\%), employer identification number, number of years of the career, retirement reason for civil servants, occupational pension benefits and for each quarter of the year we dispose as well of the variable FullTime Equivalent (=FTE). FTE is a crucial variable that indicates the effective $\mathbf{5}^{\mathbf{5}}$ number of hours worked during a given quarter, in contrast to the variable "full/part-time contract" that indicates according to what percentage somebody is officially contracted.

The sample size decreases slightly over time due to increasing number of deaths of older people over time. The red lines show when and for whom an earnings test threshold increase took place.

\begin{tabular}{|l|l|l|l|l|l|l|l|l|l|l|l|}
\hline \multicolumn{10}{|c|}{ Table 2: Sample size by calendar and age } \\
\hline age & 1999 & 2000 & 2001 & 2002 & 2003 & 2004 & 2005 & 2006 & 2007 & 2008 & 2009 \\
\hline 53 & 6945 & & & & & & & & & & \\
\hline 54 & 5752 & 6945 & & & & & & & & & \\
\hline 55 & 5693 & 5752 & 6945 & & & & & & & & \\
\hline 56 & 5421 & 5693 & 5752 & 6945 & & & & & & & \\
\hline 57 & 4681 & 5421 & 5693 & 5752 & 6945 & & & & & & \\
\hline 58 & 4347 & 4681 & 5421 & 5693 & 5752 & 6945 & & & & & \\
\hline 59 & 4582 & 4347 & 4681 & 5421 & 5693 & 5752 & 6898 & & & & \\
\hline 60 & 5084 & 4582 & 4347 & 4681 & 5421 & 5693 & 5713 & 6838 & & & \\
\hline 61 & 5237 & 5084 & 4582 & 4347 & 4681 & 5421 & 5644 & 5658 & 6768 & & \\
\hline 62 & 5018 & 5237 & 5084 & 4582 & 4347 & 4681 & 5373 & 5583 & 5609 & 6691 & \\
\hline 63 & 4694 & 5018 & 5237 & 5084 & 4582 & 4347 & 4640 & 5317 & 5519 & 5565 & 6626 \\
\hline 64 & 4543 & 4694 & 5018 & 5237 & 5084 & 4583 & 4290 & 4595 & 5269 & 5463 & 5491 \\
\hline 65 & 4496 & 4543 & 4694 & 5018 & 5237 & 5083 & 4509 & 4225 & 4517 & 5197 & 5389 \\
\hline 66 & 4552 & 4496 & 4543 & 4694 & 5018 & 5237 & 5021 & 4456 & 4171 & 4452 & 5113 \\
\hline 67 & 4572 & 4552 & 4496 & 4543 & 4694 & 5018 & 5147 & 4943 & 4381 & 4106 & 4382 \\
\hline 68 & 4383 & 4572 & 4552 & 4496 & 4543 & 4694 & 4936 & 5059 & 4862 & 4293 & 4023 \\
\hline 69 & & 4383 & 4572 & 4552 & 4496 & 4543 & 4609 & 4847 & 4962 & 4778 & 4223 \\
\hline 70 & & & 4383 & 4572 & 4552 & 4496 & 4441 & 4527 & 4763 & 4863 & 4687 \\
\hline 71 & & & & 4383 & 4572 & 4552 & 4388 & 4335 & 4426 & 4649 & 4759 \\
\hline 72 & & & & & 4383 & 4572 & 4424 & 4280 & 4228 & 4331 & 4543 \\
\hline 73 & & & & & & 4383 & 4432 & 4276 & 4169 & 4128 & 4218 \\
\hline 74 & & & & & & & 4247 & 4272 & 4141 & 4061 & 4024 \\
\hline
\end{tabular}

\footnotetext{
${ }^{4}$ It is only since 2003 that the Datawarehouse registers data from all social security institutions and hence covers $100 \%$ of the Belgian citizens. Because we want a random sample of the population the year of the selection is 2003.

${ }^{5}$ F.e. periods of illness, disability, leave, holidays, ... are excluded from effective labour supply.
} 


\begin{tabular}{|l|l|l|l|l|l|l|l|l|l|l|l|}
\hline 75 & & & & & & & & 4087 & 4116 & 4008 & 3940 \\
\hline 76 & & & & & & & & & 3929 & 3967 & 3858 \\
\hline 77 & & & & & & & & & & 3769 & 3819 \\
\hline 78 & & & & & & & & & & & 3611 \\
\hline total & 80000 & 80000 & 80000 & 80000 & 80000 & 80000 & 78712 & 77298 & 75830 & 74321 & 72706 \\
\hline
\end{tabular}

Table 3: how many people between 60-69 cumulate pension with labour income?

\begin{tabular}{|l|l|l|}
\hline Number of observations in the age category & Age 60-64 & Age 65-69 \\
\hline Who receive pension benefits & $\mathrm{N}=229400$ & $\mathrm{~N}=207703$ \\
\hline Who receive pension benefits and labour income & $\mathrm{N}=68628$ & $\mathrm{~N}=200341$ \\
\hline $\begin{array}{l}\text { Who receive pension benefits and labour income } \\
\text { (under the earnings test threshold) }\end{array}$ & $\mathrm{N}=5795$ & $\mathrm{~N}=12411$ \\
\hline
\end{tabular}

Few pensioners combine pension benefits with labour income: only $8.4 \%(=5795 / 68628)$ of all pension beneficiaries in ages 60-64 and 6.2\%(=12411/200341) of the pension beneficiaries in ages 65-69. So the mass of pensioners stays with zero hours of work. At the same time it appears that of those who cumulate pensions with labour income, $86 \%=(5003 / 5795)$ and $91 \%(=11326 / 12411)$ stay below the earnings test threshold.

As this paper focuses on the cumul of earnings with OA pension benefits ${ }^{6}$ for private wageearners and civil servants, we briefly explain their old-age pension schemes. The old-age pension scheme for private wage-earners can be claimed between the ages of 60 and 65 conditional on a career of 35 years. Pension benefit $=N / 45 *$ average lifecycle earnings $* k$, where $\mathrm{N}$ represents the number of years worked or spent on replacement income (UN, ER or disability benefits) and $k$ is a replacement rate, which takes on the value of 0.60 or 0.75 depending on whether the pension recipient claims benefits with or without a working spouse. Most men still accrue extra pension rights by working additional years between 60 and 65 because a full career consists of 45 years, a condition that many do not satisfy at 60 . For those having a career longer than 45 years, a dropout-year provision replaces low-earnings years with higher ones. Next to the official OA pension scheme, several forms of ER-programs have developed since the 1970's, based on collective agreements between employees and employers: they allow retirement at 58, $56,55,54$ or even at 52 conditional on certain career conditions and depending on the sector of activity. Those who are early retired stay in the ER-scheme until the age of 65 at which they are transferred to the OA-pension scheme. Figure 2 shows that at 60, 20\% of wage-earners draw their main income from employment, about 20\% from OA-benefits, 30\% from ER-benefits, 20\% from UN-benefits and about $10 \%$ from disability benefits. Observations concerning ERbeneficiaries will be deleted from our sample.

Figure 2: distribution labour market status of private wage-earners by age $^{7}$

\footnotetext{
${ }^{6}$ There also exists an earnings test for UN and for ER benefits. We did not include the self-employed as hours of work are not available for the self-employed. In the future, we hope however to incorporate them in a labour supply model of full-time, part-time and no work (in the vein of Zabalza et al(1980)).

${ }^{7}$ We attribute individuals a labour market status depending on their dominant income source at that time. This masks that several OA-pensioners in fact still receive earnings (up to the earnings test threshold).
} 


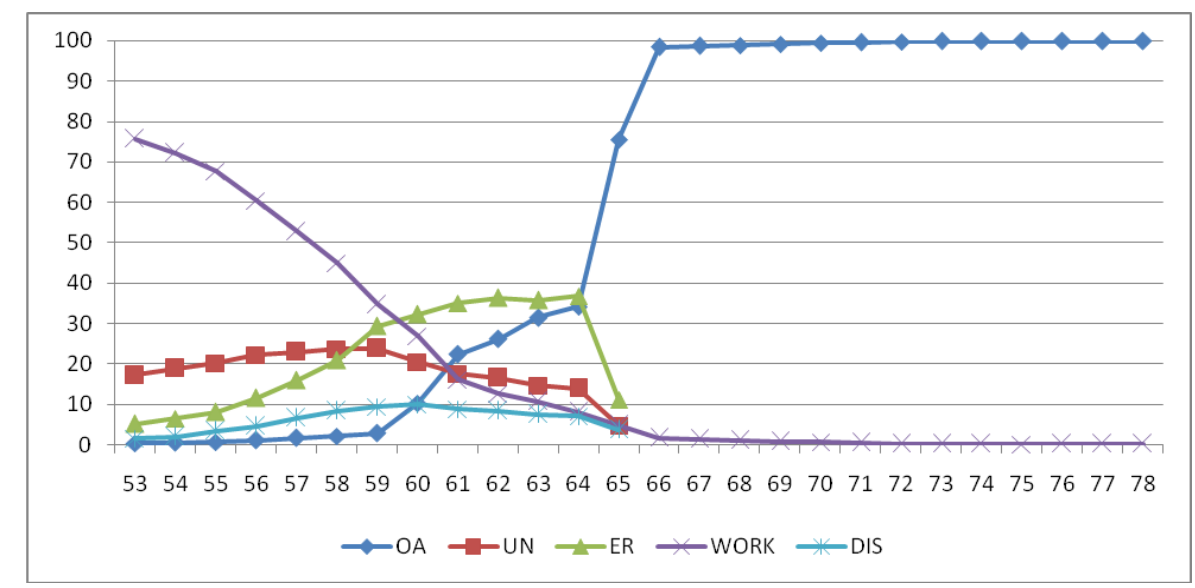

Civil servants claim OA-benefits in principle at latest at the age of 65 . However, early claiming is possible at the age of 60 conditional upon a career of 5 years. For military personnel and teachers, the NRA itself is lower than 65 (f.e. for military personnel 54 , for policemen $56, .$. ). Civil servant pensions are a percentage (which cannot exceed $75 \%$ ) of average earnings during the last five years before retirement. Hence pension benefit =average earnings over last five years*min (fract; 0.75), where fract is a fraction with a numerator consisting of the number of years the person worked in the public service, and the denominator is a benefit accrual factor. It equals f.e. 50 for policemen and firemen, 55 for teachers in secondary schools and 60 for the majority of civil servants. Aside from OA-retirement, civil servants often have the alternative to quit work early through disability pensions where the screening seems to be weak. As disability pensions are calculated exactly as OA pensions and are subject to the same earnings test, these observations are treated just like OA pensions. At the age of 56, more than $20 \%$ of them get already most of their income from OA-benefits and $95 \%$ of them at the age of 60 . Some civil servants, members of a political party, are allowed to cumulate earnings with pension benefits without any limit: they were deleted from our sample.

\section{Figure 3: Distribution of labour market status of civil servants by age ${ }^{8}$}

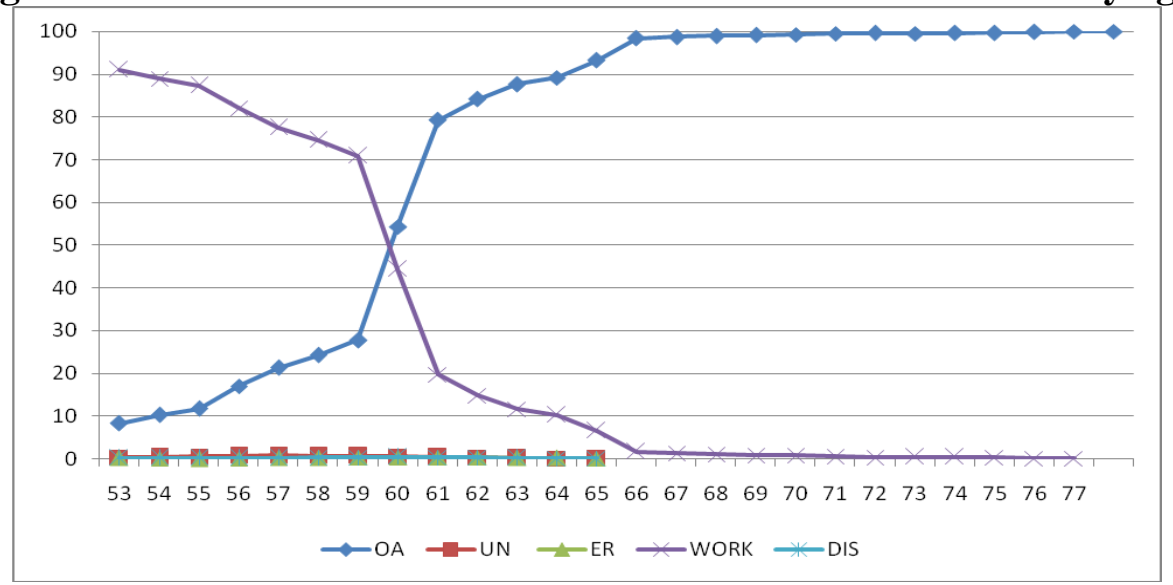

\section{Some descriptive evidence}

\footnotetext{
${ }^{8}$ Again we attribute civil servants a labour market status depending on their dominant income source at that time. Note that on average $10 \%$ of OA-retired civil servants cumulate their OA-pension with labour income.
} 
The next figures visualize the bunching phenomenon just below the earnings test threshold and how working pension beneficiaries respond to a change in the threshold. This gives us a feel of the substitution effect on labour supply as the earnings test threshold increases. We will compare the distribution of labour incomes of a treatment (65-69) and control (60-64) group in the years before any change (1999-2002) to the years 2005-2009 when the main changes took effect. In particular, we group labour incomes, in nominal terms, in intervals of 1000euros relative to the pre-reform threshold amount of 1999-2001. We only consider labour incomes of workers who cumulate this with pension benefits.

Figure 4 starts with employees above 64: there appears to be a clear concentration of labour incomes in the intervals just below the threshold in 2000-2001. Over time, as the threshold increases, earnings are spread more equally. The disappearance of the bunching also seems to increase over time. Interestingly, figure 5 shows the same data for the age group $<65$. For that age group, which we consider as a control group, bunching remains strongly in place over time. This strengthens our hypothesis that the shift in the earnings distribution for those above 65 is not driven by some macro-economic trend affecting all age groups but rather by the earnings test reform.

Figure 4: earnings of pension beneficiaries, age $>64$, relative to the exempt amount of 1999 2001

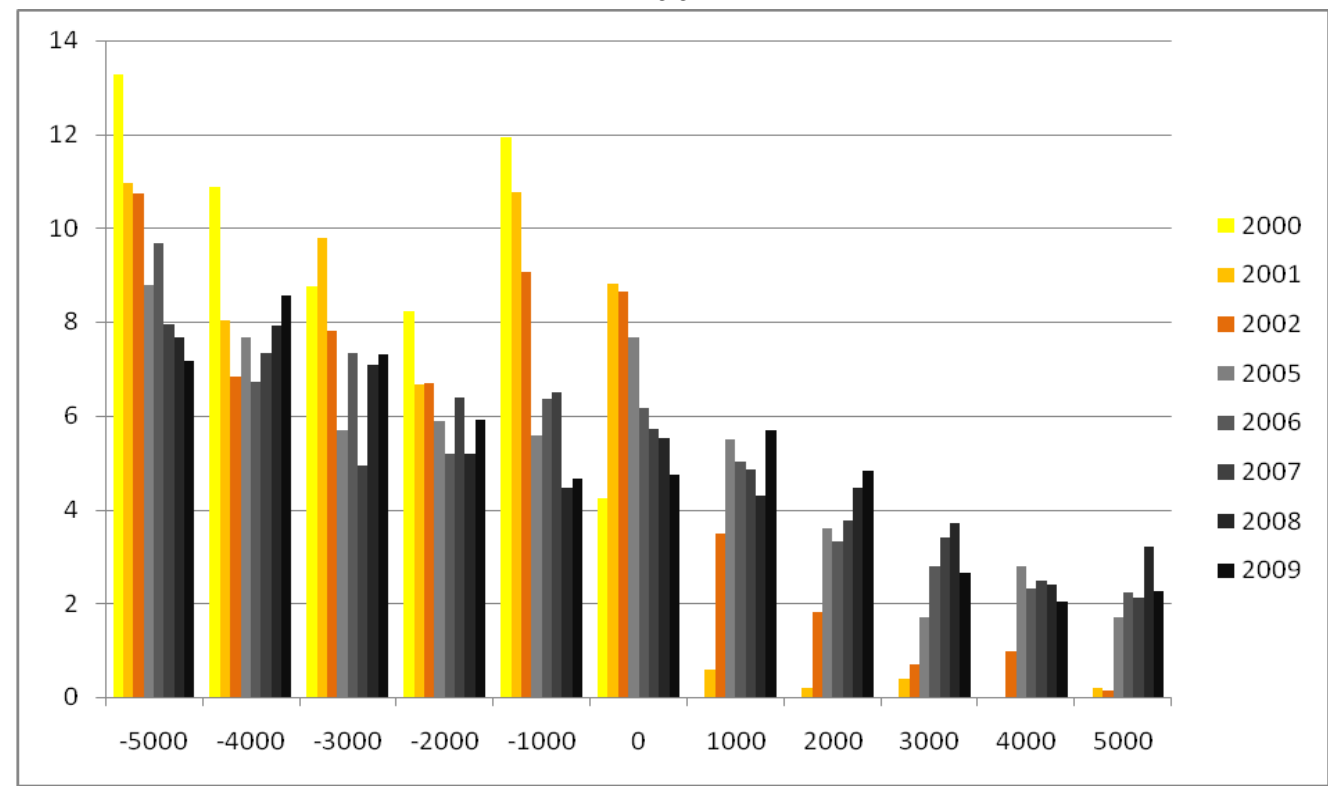

Figure 5: earnings of pension beneficiaries, age $<64$, relative to the exempt amount of 19992001 


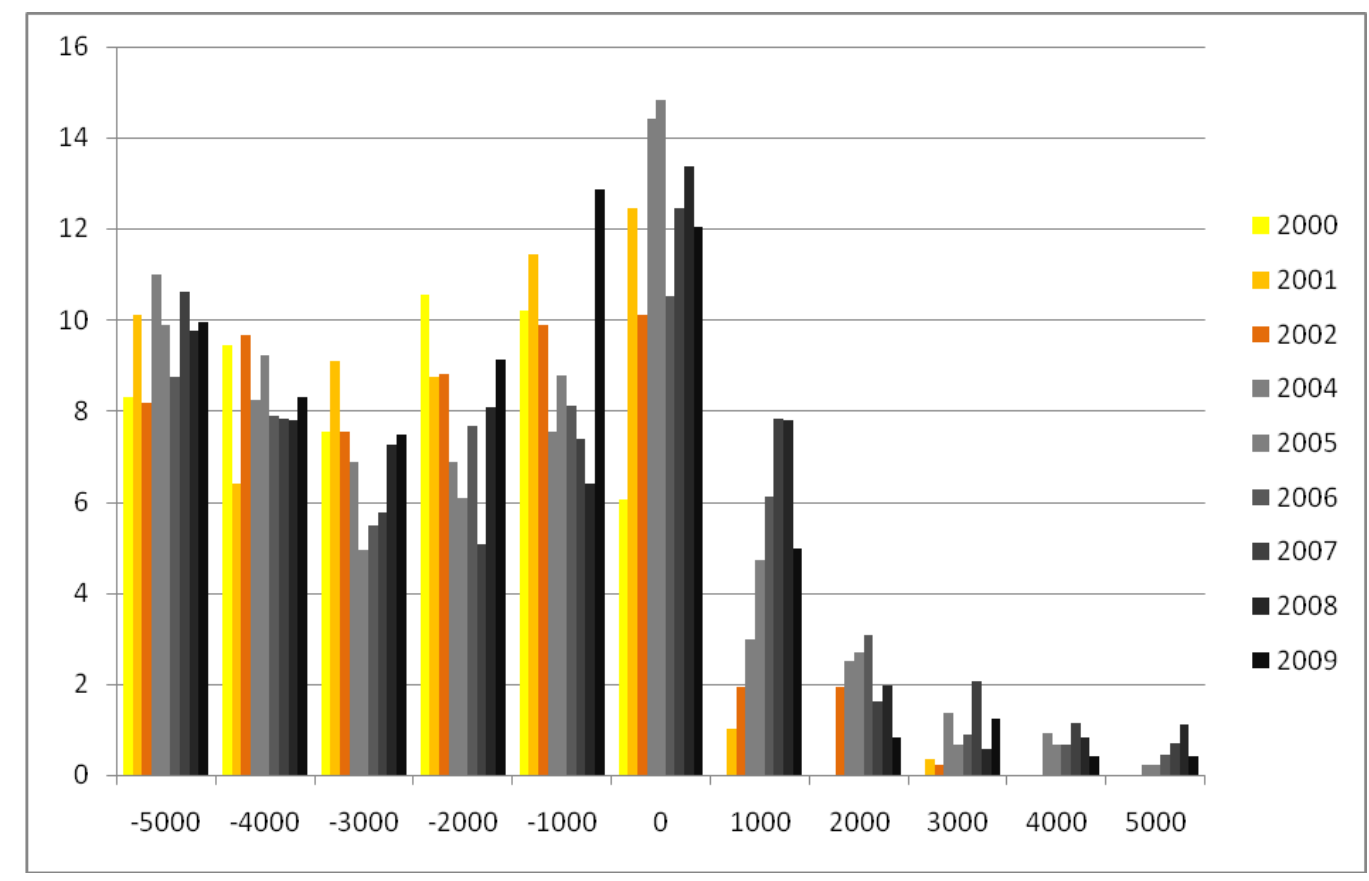

These figures visualized the bunching phenomenon just below the threshold and the strong adjustment of labour supply behaviour to the threshold. However, only a small part of the population is bunching and it remains to be seen how people located above the threshold will react in order to conclude about the aggregate impact on labour supply.

In our study, hours of work are measured by the variable FTE, i.e. the effective percentage of work supplied by an individual compared to a full-time worker. Table 4 shows the distribution of FTE by decile over time. In the age category 65-69 about $60 \%$ of employees have a FTE less than $40 \%$, this means they worked less than $40 \%$ on a yearly basis. Interestingly hours of work start to increase after the threshold reforms in all deciles, except P80. The decrease in P80 may be due to a negative income effect. Combining hours of work with the fact that employment rates among those aged 65-69 did not change, this would mean that people 65-69 that were still working at those ages will work a few hours more. Among those aged 60-64 we see that the majority of workers works fulltime. Hence there is much less variation in hours worked among workers younger than 65 than older than 65 . We also notice a small decrease of labour supplied over time in the lowest deciles.

\begin{tabular}{|c|c|c|c|c|c|c|c|c|c|}
\hline \multicolumn{10}{|c|}{ Table 4: distribution of annual FTE $>$, 65-69, over time } \\
\hline Year(observations) & P10 & P20 & P30 & P40 & P50 & P60 & P70 & P80 & P90 \\
\hline $1999(2461)$ & 0.05 & 0.10 & 0.16 & 0.23 & 0.31 & 0.38 & 0.52 & 0.83 & 1 \\
\hline $2000(2797)$ & 0.05 & 0.10 & 0.16 & 0.23 & 0.31 & 0.38 & 0.52 & 0.85 & 1 \\
\hline $2001(2821)$ & 0.04 & 0.10 & 0.15 & 0.22 & 0.3 & 0.36 & 0.5 & 0.83 & 1 \\
\hline $2002(3009)$ & 0.05 & 0.10 & 0.16 & 0.23 & 0.31 & 0.37 & 0.51 & 0.87 & 1 \\
\hline $2003(3305)$ & 0.05 & 0.10 & 0.18 & 0.24 & 0.31 & 0.37 & 0.52 & 0.81 & 1 \\
\hline $2004(3434)$ & 0.05 & 0.10 & 0.16 & 0.22 & 0.31 & 0.36 & 0.47 & 0.75 & 0.98 \\
\hline
\end{tabular}

\footnotetext{
${ }^{9}$ We first removed all observations corresponding to individuals in the first year of claiming OAbenefits.
} 


\begin{tabular}{|l|l|l|l|l|l|l|l|l|l|}
\hline $2005(3534)$ & 0.05 & 0.10 & 0.16 & 0.23 & 0.31 & 0.37 & 0.50 & 0.83 & 1 \\
\hline $2006(3433)$ & 0.06 & 0.11 & 0.18 & 0.24 & 0.32 & 0.37 & 0.55 & 0.82 & 1 \\
\hline $2007(3567)$ & 0.05 & 0.11 & 0.18 & 0.25 & 0.32 & 0.39 & 0.54 & 0.76 & 1 \\
\hline $2008(3877)$ & 0.06 & 0.12 & 0.19 & 0.25 & 0.34 & 0.43 & 0.58 & 0.84 & 1 \\
\hline $2009(4141)$ & 0.06 & 0.12 & 0.18 & 0.26 & 0.34 & 0.42 & 0.58 & 0.80 & 1 \\
\hline
\end{tabular}

\begin{tabular}{|c|c|c|c|c|c|c|c|c|c|}
\hline \multicolumn{10}{|c|}{ Table 5: Distribution of annual FTE $\mathbf{6 0 - 6 4 ,}$ over time } \\
\hline Year(observations) & P10 & P20 & P30 & P40 & P50 & P60 & P70 & P80 & P90 \\
\hline $1999(12543)$ & 0,19 & 0.39 & 0.64 & 0.83 & 0.99 & 1 & 1 & 1 & 1 \\
\hline $2000(12235)$ & 0,18 & 0.35 & 0.58 & 0.83 & 0.99 & 1 & 1 & 1 & 1 \\
\hline $2001(12380)$ & 0,20 & 0.41 & 0.66 & 0.84 & 0.99 & 1 & 1 & 1 & 1 \\
\hline $2002(13018)$ & 0,20 & 0,41 & 0.63 & 0.83 & 0.99 & 1 & 1 & 1 & 1 \\
\hline $2003(14455)$ & 0,187 & 0.41 & 0.61 & 0.83 & 0.98 & 1 & 1 & 1 & 1 \\
\hline $2004(15623)$ & 0,20 & 0.42 & 0.66 & 0.83 & 0.98 & 1 & 1 & 1 & 1 \\
\hline $2005(16690)$ & 0,19 & 0.41 & 0.65 & 0.84 & 0.99 & 1 & 1 & 1 & 1 \\
\hline $2006(19403)$ & 0,20 & 0.44 & 0.67 & 0.84 & 0.99 & 1 & 1 & 1 & 1 \\
\hline $2007(12934)$ & 0,17 & 0.41 & 0.64 & 0.89 & 0.99 & 1 & 1 & 1 & 1 \\
\hline $2008(9110)$ & 0,165 & 0.35 & 0.56 & 0.83 & 0.99 & 1 & 1 & 1 & 1 \\
\hline $2009(5724)$ & 0,165 & 0.34 & 0.54 & 0.8 & 0.98 & 1 & 1 & 1 & 1 \\
\hline
\end{tabular}

To find out whether the numbers in tables 4 and 5 point to a causal impact of the earnings test reform on hours of work, we estimated a difference-in-difference model in section 4 similar to Disney-Smith(2002), Benjamin-Baker(1999), Song-Manchester(2007), Haider-Loughran(2008), Gruber-Orszag(2003).

It may also be interesting to note that the sharp drop in hours of work between those aged 60-64 and those over age 65 corresponds to a sharp increase of the share of full-time workers to parttime workers.

Figure 6: Percentage of employees who are employed on a part-time basis by age and over time 


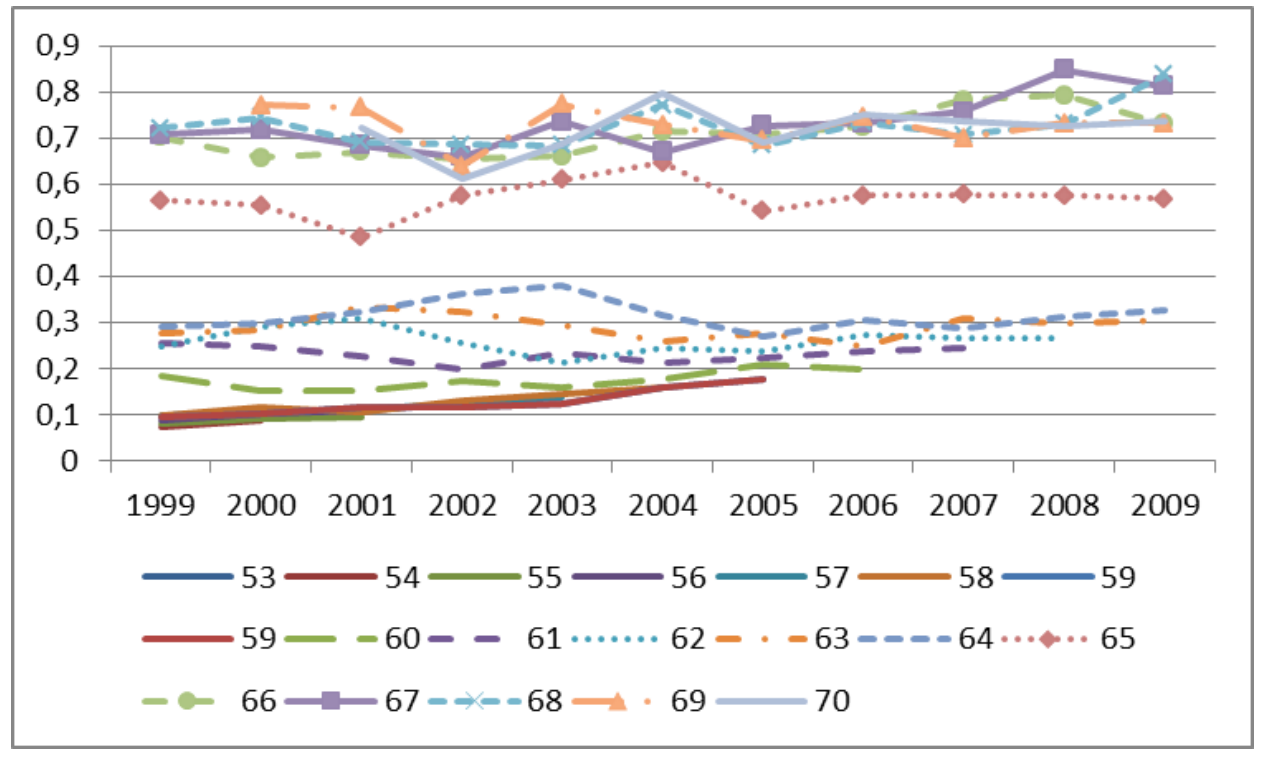

There is a strong division around the NRA. Cumulating work with take up of pension benefits, may require those employees to switch from a full-time to a part-time job and this cumul is, ceteris paribus, more frequent over the age of 65. Alternatively, this might reflect that full-time workers stop working at latest at the age of 65 while part-time workers work longer. If the earnings test reform would lead to more cumul of benefits with part-time work we would see a sharper increase of part-time workers in the age group 65-69 after 2002/2004/2006/2007 and not in the control group 60-64. However, it is not obvious to see whether the increase in part-time is stronger among those 65-69 than those 60-64: a difference-in-difference analysis would perhaps also be helpful.

\section{Impact on hours of work: a difference-in-difference approach}

A difference-in-difference analysis requires the specification of a control and a treatment group. The control (treatment) group consists of all observations of individuals older than 65 before (after) the year of policy reform. However, it is not sufficient to compare the variables of interest of those groups alone. Differences in behaviour before and after the reform could be due to business-cycle effects. In order to identify the causal effects of policy reform, we use, as Manchester-Song(2007), Benjamin-Baker(1999), Disney-Smith(2002), additional control groups aged between 60-64 years before and after the year of reform. If this is a suitable control group we expect the same trend evolution in hours of work among those aged 60-64 and those aged above 65 in the period before the reform ${ }^{10}$.

We estimate a censored OLS regression on a sample with zero hours and positive hours of work (as Song-Manchester(2007), Blundell-Smith(2002), Haider-Louchran(2007), Baker$\operatorname{Benjamin}(1999))$ :

\footnotetext{
${ }^{10}$ We did not assess whether the relaxation of the earnings test for those aged 65 and over affects the labour supply of the group aged 60-64 as they might anticipate changes in the earnings test, as demonstrated by Michaud-Van Soest(2007).
} 


$$
y_{i t}=\beta_{0}+\beta_{1} I N C_{i t}+\beta_{2} A g e_{t}+\beta_{3} \text { Year }_{t}+\beta_{4} X_{i t}+\varepsilon_{i t}
$$

Where $\mathrm{INC}_{\mathrm{it}}$ is an indicator variable for whether individual $\mathrm{i}$ in year $\mathrm{t}$ is in an age group for whom the earnings test threshold was increased. $\mathrm{INC}_{\mathrm{it}}=1$ if individual $\mathrm{i}$ is older than 64 after year $\mathrm{t}$ and $=0$ if individual is younger than 65 in year $\mathrm{t}$. The "treatment" depends on both time and age. Since effects immediately after the reform may differ from later effects, we use as Song-Manchester(2007) a treatment dummy for different years after the reform instead of one post-reform dummy. We also include, as a sort of specification test, false treatment dummies (concerning the years before the reform) which should be insignificant if we want to interpret the treatment dummies as truly treatment effects. $X_{i t}$ is a vector of individual-specific time varying characteristics (like region, marital status, NACE code, ...), $A g e_{i t}$ is a vector of age dummies, Year $_{t}$ is a vector of year dummies. The dependent variable $y_{i t}$ represents annual FTE. The coefficient of interest is $\beta_{1}$ which measures the effect of increasing the threshold on the treated age group.

We found a significant treatment effect of the threshold increase on hours of work. Interestingly the false treatment dummies are insignificant what strengthens our hypothesis that the treatment dummies truly capture the impact of the earnings test reform.

\begin{tabular}{|lccc|}
\hline \multicolumn{4}{c}{ Table 6: estimation results difference-in-difference model } \\
\hline variable & Estimate & Error & Pr $>|t|$ \\
& & & \\
\hline Intercept & 1.937222 & 0.048983 & $<.0001$ \\
\hline falsetreatment00 & 0.154325 & 0.114248 & 0.1768 \\
\hline falsetreatment01 & -0.104629 & 0.111608 & 0.3485 \\
\hline treatment03 & $\mathbf{0 . 3 1 3 0 6 3}$ & $\mathbf{0 . 1 0 5 6 7 8}$ & $\mathbf{0 . 0 0 3 1}$ \\
\hline treatment04 & $\mathbf{0 . 1 3 1 1 5 3}$ & $\mathbf{0 . 1 0 5 5 7 3}$ & $\mathbf{0 . 2 1 4 1}$ \\
\hline treatment05 & $\mathbf{0 . 3 7 6 7 1 4}$ & $\mathbf{0 . 1 0 7 2 9 9}$ & $\mathbf{0 . 0 0 0 4}$ \\
\hline treatment06 & $\mathbf{0 . 4 7 2 6 8 7}$ & $\mathbf{0 . 1 0 7 5 2 3}$ & $<.0001$ \\
\hline treatment07 & $\mathbf{0 . 5 3 4 9 0 8}$ & $\mathbf{0 . 1 1 3 0 7 0}$ & $<.0001$ \\
\hline treatment08 & $\mathbf{0 . 7 2 2 0 7 8}$ & $\mathbf{0 . 1 0 2 6 0 8}$ & $<.0001$ \\
\hline cohort born before 38 & 0.204360 & 0.045274 & $<.0001$ \\
\hline cohort born after 46 & -0.033484 & 0.042739 & 0.4334 \\
\hline age 61 & 0.101650 & 0.033820 & 0.0027 \\
\hline age 62 & 0.049507 & 0.037860 & 0.1910 \\
\hline age 63 & -0.119526 & 0.042477 & 0.0049 \\
\hline age 64 & -0.223433 & 0.047681 & $<.0001$ \\
\hline age 65 & -1.327666 & 0.090171 & $<.0001$ \\
\hline age 66 & -1.566135 & 0.098863 & $<.0001$ \\
\hline age 67 & -1.531529 & 0.104100 & $<.0001$ \\
\hline age 68 & -1.505803 & 0.107843 & $<.0001$ \\
\hline age 69 & -1.644968 & 0.112001 & $<.0001$ \\
\hline
\end{tabular}




\begin{tabular}{|c|c|c|c|}
\hline year 00 & -0.449961 & 0.056567 & $<.0001$ \\
\hline year 01 & -0.281840 & 0.057672 & $<.0001$ \\
\hline year 02 & -0.328620 & 0.057936 & $<.0001$ \\
\hline year 03 & -0.660164 & 0.060555 & $<.0001$ \\
\hline year 04 & -0.668583 & 0.063747 & $<.0001$ \\
\hline year 05 & -0.785834 & 0.066597 & $<.0001$ \\
\hline year 06 & -0.819615 & 0.068357 & $<.0001$ \\
\hline year 07 & -0.974424 & 0.080494 & $<.0001$ \\
\hline year 08 & -1.089041 & 0.085618 & $<.0001$ \\
\hline year 09 & -1.104395 & 0.092794 & $<.0001$ \\
\hline Sigma & 1.937756 & 0.007165 & $<.0001$ \\
\hline \multicolumn{4}{|c|}{$\begin{array}{l}\text { The estimation also controlled for serial dependence of the error terms at the individual level. Number of } \\
\text { Observations: } 42148 \text {; censored values: } 447163 \text {, mean annual FTE: } 0.54 \text {, Log Likelihood= }-83339 \text {. We also } \\
\text { controlled for sector of activity. The reference category is year 1999, age 60, in sector } 3 \text { and } 4 \text {, born between } 1938 \text { - } \\
\text { 1943. We select the individuals eligible for OA-benefits (hence older than } 59 \text { with a career of 35years) and exclude } \\
\text { self-employed and fully retired individuals with zero hours in first year of observation. }\end{array}$} \\
\hline
\end{tabular}

\section{Estimation of a structural labour supply model}

The difference-in-difference analysis of the previous section confirms that the natural experiment caused an increase of hours of work. However it does not allow us to disentangle income and substitution effects on labour supply. Therefore we need a structural labour supply model. That would be especially interesting given the problem at hand as we suspect that aggregate labour supply responses to the earnings test reforms may be small but that nonetheless there are for some individuals significant income and for other individuals significant substitution effects that partly offset each other in the aggregate. The rare applications that we found of structural labour supply models to the earnings test, and hence on a sample of individuals who are upon to retire, are those of Friedberg(2000), Burtless-Moffit(1985), Gustman-Steinmeier(2004) and ZabalzaPissarides-Barton(1980).

In this paper we follow the approach of Friedberg(2000) who applies the one-period BurtlessHausman(1978) labour supply model. It assumes that an individual i's weekly ${ }^{11}$ hours of work $H_{i}$ are determined by the following linear relationship ${ }^{12}$ :

$$
H_{i}=\beta_{0}+\beta_{1} X_{i}+\beta_{2} W(1-\tau)_{i}+\beta_{3} Y_{V i}+\alpha_{i}
$$

With $W_{i}\left(1-\tau_{i}\right)$ net wage per hour, $Y_{V i}$ yearly virtual income, $X_{i}$ a vector of individual characteristics (a linear age variable and a dummy for age over/below 65, 17 dummies for sector of activity, number of household members, a dummy for having been unemployed previously, 2 regional dummies) and $\alpha$ a random variable that represents heterogeneity in preferences. As explained by Moffit(1986), "heterogeneity of preferences tends to generate clusters of

\footnotetext{
${ }^{11}$ We converted FTE in a measure of hours of work per week, given that there are 52 weeks in a year and 40hours of work per week for a full-time contract: FTE*40/52.

${ }^{12}$ We dropped the time indices $t$.
} 
observations at the kink of a convex budget constraint and tends to disperse observations away from the kink of a nonconvex budget constraint"(p.321). In particular it accounts for the fact that the convex kink in our budget constraint is compatible with an entire range of utility functions. Given the way our budget constraint looks like (see figure 1), allowing for heterogeneous preferences may be necessary. Given the Belgian earnings test rules, the net wage $w(1-\tau)$ and virtual income $Y_{V}$ are defined as follows:

$\tau=0, Y_{V}=$ pension+capital income

$\tau=100 \%, Y_{V}=$ pension +capital income+threshold

$\tau=0, Y_{V}=$ capital income if earnings $<$ threshold

if threshold < earnings < threshold $* 1.15$

if earnings $>$ threshold* 1.15

The estimation of this equation by OLS would lead to biased estimates. This is because net wage and virtual incomes are determined by the number of hours that an individual works. Individuals with a greater taste for work will work more hours and end up with lower net wage and higher virtual income. Thus the error term will be systematically correlated with the wage and virtual income variables and result in inconsistent estimates. To overcome this endogeneity problem, we follow, like Friedberg(2000), the proposal of Burtless-Hausman(1978) to construct for every individual in the sample its whole piecewise-linear budget constraint. The idea is that by taking into account the entire exogenous budget constraint, one removes the endogeneity that is associated with the joint choice of hours and net wage in a particular segment of the constraint. This involves defining for each individual a set of virtual incomes and net wages depending on the segment of the budget constraint where he may locate. Assuming that $\alpha$ is standard normally distributed $\mathrm{N}\left(0, \sigma_{\alpha}^{2}\right)$, we write down for each individual the following log-likelihood which includes the different segments (defined by their corresponding virtual income and net wage) where the individual may choose to locate:

$$
\begin{aligned}
& \log \left(\mathrm{H}_{\mathrm{i}}\right)=S_{1 i} \log \left[\frac{1}{\sigma_{\alpha}} \phi\left(\frac{\alpha_{i}=H_{i}-Z_{1 i} \theta}{\sigma_{\alpha}}\right)\right]+K_{i} \log \left[\int_{H i-Z_{1 i} \theta}^{H i-Z_{2 i} \theta} \frac{1}{\sigma_{\alpha}} \phi\left(\frac{\alpha_{i}}{\sigma_{\alpha}}\right)\right]+ \\
& S_{2 i} \log \left[\frac{1}{\sigma_{\alpha}} \phi\left(\frac{\alpha_{i}=H_{i}-Z_{2 i} \theta}{\sigma_{\alpha}}\right) \Phi\left(\alpha^{\prime}\right)\right]+S_{3 i} \log \left[\frac{1}{\sigma_{\alpha}} \phi\left(\frac{\alpha_{i}=H_{i}-Z_{3 i} \theta}{\sigma_{\alpha}}\right)\left(1-\Phi\left(\alpha^{\prime}\right)\right]\right. \\
& -\log \left[1-\int_{-\infty}^{-Z_{1} \theta} \frac{1}{\sigma_{\alpha}} \phi\left(\frac{\alpha_{i}}{\sigma_{\alpha}}\right) d \alpha_{i}\right]
\end{aligned}
$$

With $Z_{j i} \theta=\beta_{0}+\beta_{1} X_{i}+\beta_{2} W(1-\tau)_{i}+\beta_{3} Y_{V i}$ for $\mathrm{j}=1,2,3$ depending on the segment of the piecewise-budget constraint, $\phi$ the standard normal pdf and $\Phi$ the cdf. Each element of this equation is multiplied by an indicator variable $S_{1 \mathrm{i}}, S_{2 \mathrm{i}}$ or $S_{3 \mathrm{i}}$ for the budget segment where the individual is located or the indicator variable $\mathrm{K}_{\mathrm{i}}$ when the individual is situated on the convex kink. Individuals are attributed to the kink if they have hours of work in an interval between $\mathrm{h}^{*}$ and $h^{*}-3.84$ hours per week. Nobody is situated on the nonconvex kink. Note that $\alpha^{\prime}$ stands for the value of $\alpha$ which makes the individual indifferent between the horizontal segment and the segment above the threshold. Its value is obtained by juxtaposing the indirect utility function 
corresponding to a location at the horizontal segment with that if the individual were located at the upper segment. Then we maximize the sum of these individual likelihoods.

Table 7 shows that about $72 \%$ of our sample have zero hours, $1.26 \%$ are bunching and $20 \%$ are working hours above the threshold. As Friedberg(2000), we did not include individuals with zero hours.

\begin{tabular}{|c|c|c|}
\hline \multicolumn{3}{|c|}{ Table 7: summary statistics } \\
\hline & All (hours of work $>=0$ ) & Working (hours of work $>0$ ) \\
\hline Number of observations & 83205 & 23239 \\
\hline Age $60-64$ & $57.6 \%$ & $77.09 \%$ \\
\hline Age 65-69 & $36.12 \%$ & $16.74 \%$ \\
\hline Age 70+ & $6.28 \%$ & $6.17 \%$ \\
\hline $\begin{array}{lll}\text { Having } & \text { been } & \text { unemployed } \\
\text { previously } & & \\
\end{array}$ & $10.07 \%$ & $12.88 \%$ \\
\hline Walloon & $30.06 \%$ & $29.92 \%$ \\
\hline Brussels & $6.87 \%$ & $8.55 \%$ \\
\hline Flemish & $63,07 \%$ & $61.53 \%$ \\
\hline Private sector & $54.69 \%$ & $71.79 \%$ \\
\hline Public sector & $45.31 \%$ & $28.21 \%$ \\
\hline Single & $12.39 \%$ & $13.37 \%$ \\
\hline Number household members $=1$ & $78.25 \%$ & $72.89 \%$ \\
\hline Number household members $=2$ & $15.58 \%$ & $18.40 \%$ \\
\hline Number household members $>2$ & $6.17 \%$ & $8.71 \%$ \\
\hline Mean hours per week & 8,07 & 28.8 \\
\hline Mean virtual wage per hour & 13.56 & 13.10 \\
\hline $\begin{array}{l}\text { Mean virtual income per } \\
\text { year(/1000) }\end{array}$ & 18.99 & 6.13 \\
\hline \multicolumn{3}{|c|}{ Location on budget constraint: } \\
\hline Zero hours & $72.07 \%$ & I \\
\hline $\begin{array}{l}\text { Segment between zero and } \\
\text { convex kink }\end{array}$ & $6.71 \%$ & $24.02 \%$ \\
\hline Convex kink & $1.26 \%$ & $4.52 \%$ \\
\hline Middle horizontal segment & $0.13 \%$ & $0.48 \%$ \\
\hline Upper segment & $19.81 \%$ & $70.95 \%$ \\
\hline
\end{tabular}


individuals without pension benefits while having earnings less than the threshold because the reason for not claiming is not related to the earnings test, of individuals in the year they claim OAbenefits because they have in that year also some labourincome but, as we have only yearly data, we are unable to identify whether this labour income is earned before the exact data of claiming or afterwards.

Table 8 displays the estimation results

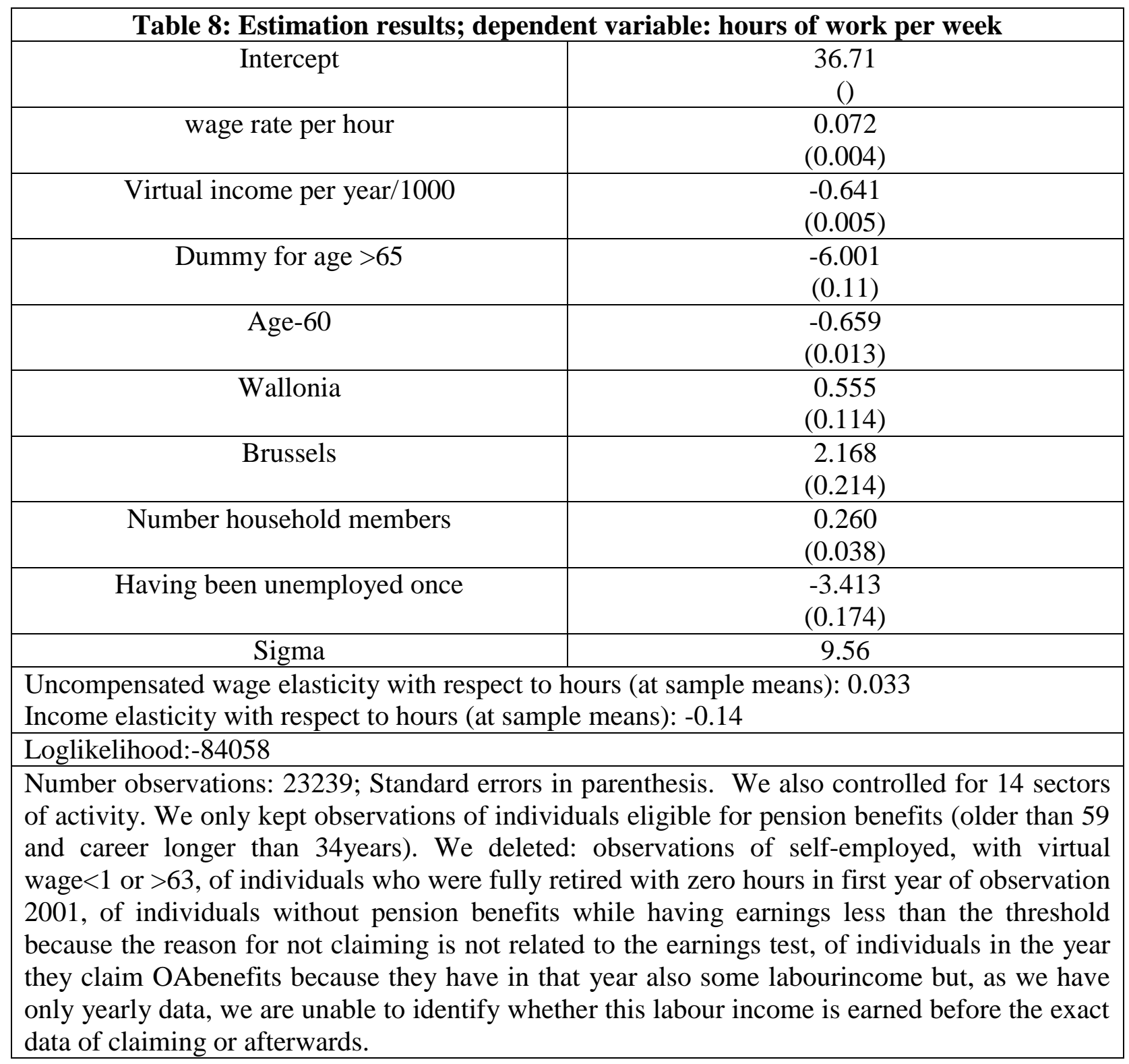

To measure the overall goodness of fit of the estimation we make use of several indicators. We look at the actual and predicted distributions of observations across the different segments of the budget constraint, as Zabalza et al.(1980). About $86 \%$ of all observations are correctly predicted on the segment they are actually located. Of those individuals located below the threshold, $72 \%$ were correctly predicted to be below the threshold. Of those individuals above $115 \%$ of the 
threshold, $96 \%$ were correctly predicted to be in that segment. However of the few individuals located at the kink or at the horizontal segment, the percentage correctly predicted is small. These results are in line with those of Zabalza et al.(1980) who also easily predicted people in full-time work and full-time retirement but only predicted $10 \%$ of the part-time working pension beneficiaries correctly.

In contrast to Zabalza et al.(1980) we estimated however a continuous distribution of hours. The following figures allow a visual comparison of the distribution of actual and of predicted ${ }^{13}$ hours of work per week. We show these distributions for each segment of the budget constraint. It shows that, although few people at the kink and in the horizontal segment were predicted to be exactly at that kink and exactly in that small horizontal segment, the predicted distribution of hours corresponds relatively well to that of the actual distribution of hours. It also shows that our model reproduces fairly well the spikes at full-time work. It overpredicts the number of hours for those at the kink and at the lower segment.

Figure 7: Segment above the threshold

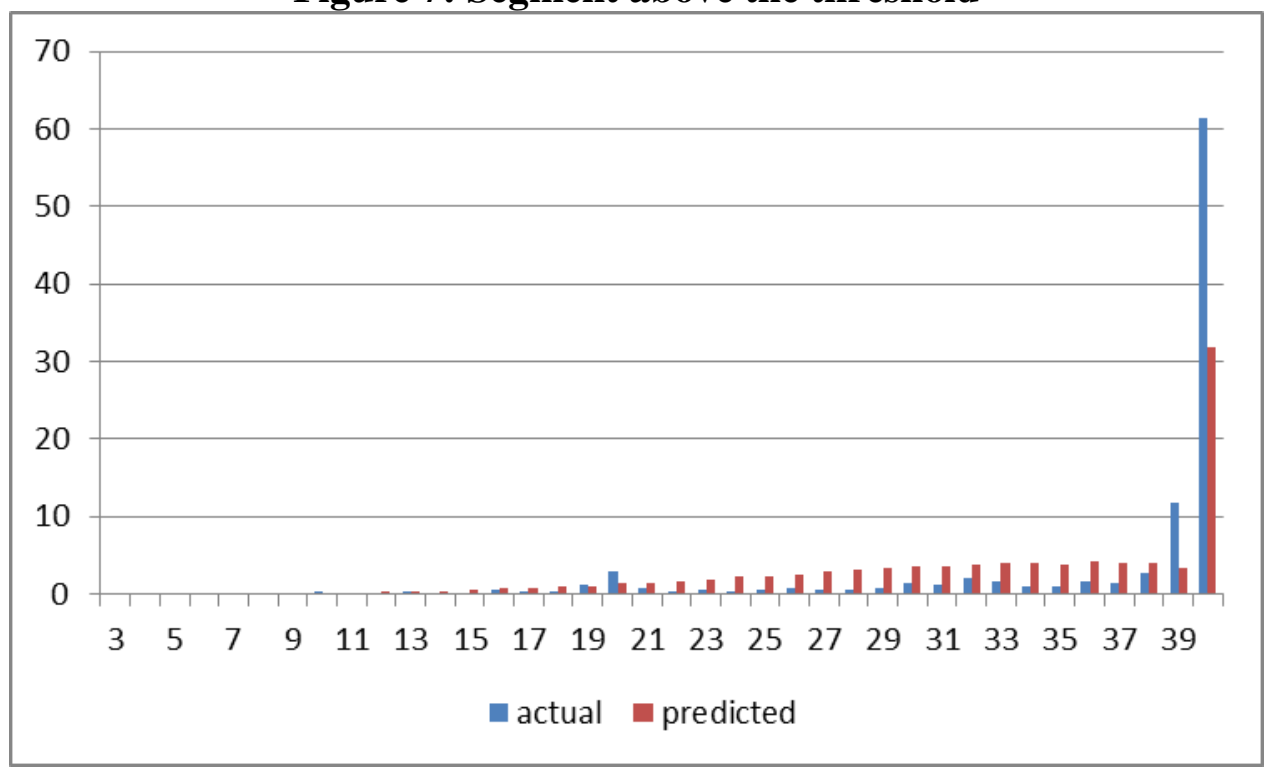

Figure 8: Kink

\footnotetext{
${ }^{13}$ We simulated a random distribution of alfa with $\mathrm{N}(0$, sigma).
} 




Figure 10: Segment below the threshold

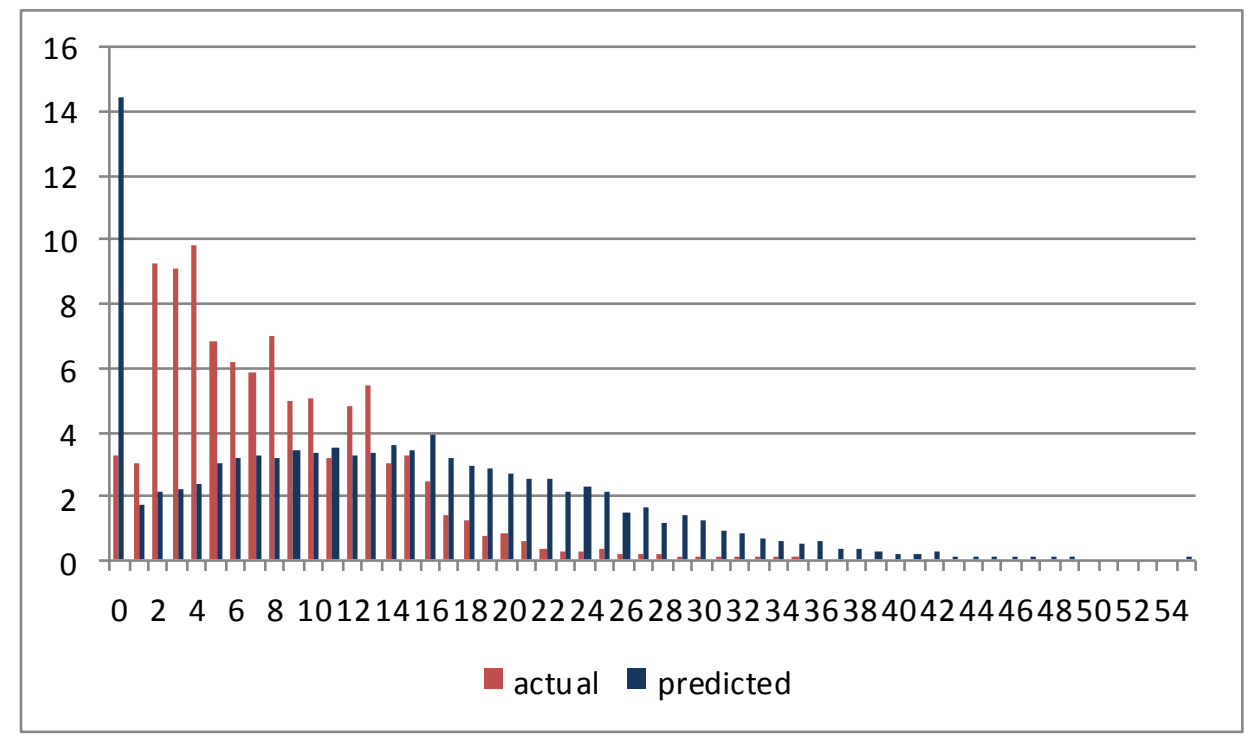


Figure 11:Horizontal segment between the threshold and threshold*1.15:

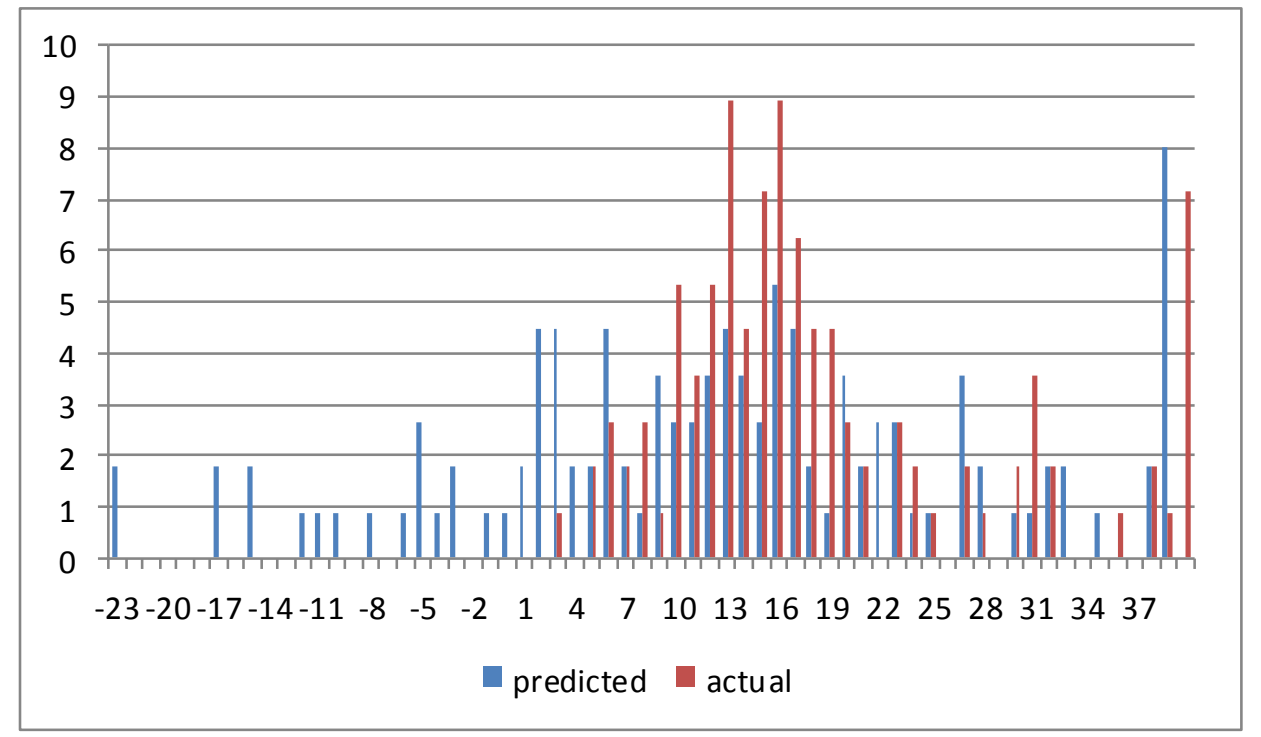

The results of interest concern the coefficients of the wage and virtual income variables. We found at the sample means (only composed of men) an uncompensated wage elasticity of 0.033 which is, as usual, very small and which suggests a forward bending labour supply curve. The income elasticity is much higher in magnitude, in line with results of the literature, and equals 0.14 .

We found it useful to compare these magnitudes to those of other structural models of labour supply that explicitly integrated the earnings test. Friedberg(2000) estimated exactly the same model, hence with continuous hours distribution, and found at the sample means an uncompensated wage elasticity of 0.225 and an income elasticity of -0.297 . A different model is that of Zabalza et al.(1980) who estimate a labour supply model using the BurtlessHausman(1978) techniques by distinguishing between 3 discrete states: full-time work, part-time work and full-time retirement. They obtained for men a wage elasticity of -0.020 ("familiar backward bending shape with a very small elasticity",p.261)) and an income elasticity of -0.023 . Interestingly, as they suspected the legal retirement age of 65 to affect their results, they estimated the regression separately on men younger than 65 and older than 64 . The wage elasticity is -0.0078 at age 59 but increases to 0.012 at age 68 : the backward bending curve was caused by the influence of men under the age of 65. Burtless-Moffit(1985) found an uncompensated wage elasticity of 0.028 and an income elasticity of -0.428 . They estimated a two-equation model that jointly estimates a retirement age and postretirement hours of work using the Burtless-Hausman(1978) techniques. Interestingly they allow the impact of virtual wage and virtual income on postretirement hours of work to depend explicitly on the age and found that a higher age increases the impact of virtual income and decreases the impact of wages on hours of work. An interesting extension for our purpose seems this Burtless-Moffit (1985) model. It extends the Friedberg-model by estimating simultaneously hours of work after retirement with the retirement decision itself. Since their definition of hours of work concerns postretirement hours of work, this would imply that the estimation of our hours of work equation would exclude those above the threshold and that the retirement equation would be estimated on the whole sample, instead of a truncated sample as we do. 


\section{Policy simulations}

The estimates of section 5 can be used to carry out policy simulations of further changes in the earnings-test rules. In particular, we simulated the impact of a complete removal of the earnings test on the number of hours worked per week, depending on the age category in which the individual is situated (below or over 65years old). The results are in table 9.

\begin{tabular}{|l|c|c|c|c|c|c|}
\hline \multicolumn{6}{|c|}{ Table 9: simulated and actual distribution of hours of work per week } \\
\hline $\begin{array}{l}\text { Percentile } \\
\text { in the hours } \\
\text { distribution }\end{array}$ & Simulated & actual & \multicolumn{2}{|c|}{ Age 65 and over } & \multicolumn{2}{c|}{ Age 60-64 } \\
\cline { 4 - 7 } & & simulated & actual & simulated & Actual \\
\hline $90 \%$ & 39 & 40 & 26.9 & 40 & 40 & 40 \\
\hline $75 \%$ & 31 & 40 & 20.13 & 15.7 & 33.8 & 40 \\
\hline $50 \%$ & 23.06 & 39.6 & 12.5 & 9.6 & 25.95 & 40 \\
\hline $25 \%$ & 13.88 & 14.6 & 4.58 & 4.8 & 18.09 & 32 \\
\hline $10 \%$ & 5.54 & 5.5 & -2.2 & 2.7 & 5.5 & 12.9 \\
\hline Mean & 22.54 & 28.8 & 12.34 & 13.16 & 25.17 & 33.5 \\
\hline
\end{tabular}

The results seem quite interesting and according to what we intuitively expect. A removal of the earnings test threshold for those 65 or older than 65 would lead to an increase of median hours worked per week with 2.9 hours per week(from 9.6 to 12.5 ) and in the $75 \%$ percentile even with 4.43hours (from 15.7 to 20.13) ${ }^{14}$. This suggests that among this age category the substitution effect dominates the income effect as one could expect because the bunching individuals are mainly in this category. This is fully in line with f.e. Friedberg(2000). However a removal of the earnings test threshold in the age group below 65 would lead to a strong decrease of hours worked: this suggests that the negative income effect plays an important role in this age group, as can be expected because these individuals are dominantly situated in the segment above the threshold. In the age category 60-64 a removal of the earnings test would hence also lead to advanced claiming of pension benefits ${ }^{15}$.

To quantify the budgetary impact of the removal of the earnings test, one should combine the impact on social contributions with the impact on the age of claiming pension benefits. Our results show that a removal of the earnings test threshold over 60 would have unambiguously a negative impact on the budget as both hours of work decrease and claiming is advanced. On the one hand a decline in number of hours worked decreases revenues for the government coming from social contributions. On the other hand, advanced claiming of pension benefits means that pension benefits have to be paid out during a longer retirement period. A removal of the earnings test above the age of 65 has an ambiguous impact on the governments' budget: it increases social contributions revenues (coming from those up to the $75^{\text {th }}$ percentile due to a

\footnotetext{
${ }^{14}$ Average hours of work would decrease slightly from 13.16 to 12.34 hours a week because some individuals are predicted to have negative hours of work while the actual distribution does not allow negative values of hours of work: if we would set the minimum of predicted hours equal to zero then average hours would increase after the earnings test removal.

${ }^{15}$ In another paper we already estimated a difference-in-difference model on claiming which learns us that the threshold increase led to a considerable and significant advanced claiming of pension benefits.
} 
substitution effect) but lengthens the period during which pension benefits have to be paid (as those above the $75^{\text {th }}$ percentile decrease their hours of work from 40 to 26.9 due to an income effect).

Finally, the case against a removal of the earnings test weakens if the Belgian pension system were actuarially fair at the margin. In that case, as it would penalize early claiming as in the UK and US system, the negative income effect would have only a marginal impact on the simulations. This explains the differences of our simulated outcomes compared to those from studies that simulate an earnings test removal in the (nearly) actuarially fair US and UK pension system (like Friedberg(2000), Burtless-Moffit(1985), Disney-Smith(2001)).

\section{Conclusion}

The earnings test which taxes away pension benefits of those who continue an economic activity is commonly perceived as a powerful work disincentive which should be abolished as soon as possible. Nonetheless, the international literature, both theoretical models and empirical applications, shows that the earnings test and its removal have an ambiguous and very modest impact on labour supply. The aim of our study was to examine the impact of the increase in the earnings test threshold that took place in the last decade on the labour supply of older people in Belgium. This throws a new light on empirical estimates as actuarial fair adjustments of pension benefits in case of deferral are nearly absent in Belgium. The bulk of empirical research concentrates on US and UK, countries which are known for having old-age pension systems that are almost actuarially fair at the margin and where as a consequence a very small income effect has a limited effect on labour supply and benefit claiming behaviour.

On the basis of longitudinal Belgian administrative data, we provide in a preliminary stage evidence of a clear bunching phenomenon just below the threshold. We also document increased labour supply of those bunching following a relaxation of the threshold. This reflects a substitution effect on labour supply. The aggregate impact depends however also on the negative income effect that affects those who, before the reform, were supplying hours of work well above the threshold and who, following a relaxation of the threshold, may decide to reduce hours of work. A structural labour supply model was estimated that accounts for a piecewiselinear budget constraint (with a convex and a nonconvex kink) and heterogenous preferences. It allows to conclude about the aggregate impact on hours of work while disentangling income and substitution effects. We found a significant income elasticity on labour supply as well as a significant wage elasticity, the latter being much smaller in magnitude. Of course, the fact that our data cover the period before and after a reform provides us with a natural experiment and makes it easier to identify these effects.

The estimates are used for policy simulations. A complete removal of the earnings test over age 65 (=normal retirement age) would increase median hours of work per week with 2.9 as a majority in this age category faces a positive substitution effect that outweighs the income effect that affects only a minority of employeess. However, a removal of the threshold over age 60 (=age of eligibility) would decrease median hours of work from 40 to 25,95 as most employees in this age category experience a negative income effect while few employees in this 
age category face a positive substitution effect. The budgetary impact for the government is also considered.

Much more work has to be done in future research. In a first step, we try to integrate a measurement error in the estimation. Secondly, when we will have more income data at our disposal, we will be able to integrate the self-employed in the analysis.

\section{References}

Benjamin, M.- Baker, D.(1999), “How do retirement tests affect the labor supply of older men?”, Journal of public economics 71(1), 27-51.

Blomquist,N.-Hansson-Brusewitz(1990), "The effect of taxes on male and female labor supply in Sweden", Journal of human resources, 317-357.

Blomquist,N.(1995), "Restrictions in labor supply estimation: is the MaCurdy critique correct?", Economics Letters, 47, 229-235.

Bourguignon,F.-Magnac, T.(1990), "Labor supply and taxation in France", The Journal of human resources, 358-389.

Burtless, G.-Hausmann, J.(1978), "The effect of taxation on labor supply: evaluating the Gary negative income tax experiment”, The Journal of Political Economy 86(6), 1103-1130.

Burtless, G.-Moffitt,R.(1985), The joint choice of retirement age and postretirement hours of work", Journal of Labor Economics, 3(2), 209-236.

Disney,R.- Smith,S.(2002), "The labor supply effect of the abolition of the earnings rule for older workers in the United Kingdom”, Economic Journal 112(478), C136-52.

Ecklof-Sacklén(2000), "The Hausman-MaCurdy controversy: why do the results differ across studies?", Journal of Human resources 35(1), 204-220.

Gruber, J.-Orszag, M.(2003), "Does the social security earnings test affect labor supply and benefits receipt?”, National Tax Journal LVI(4), 755-773 .

Friedberg, L.(2000), "The labor supply effects of the social security earnings test", Review of economics and statistics 82(1), 48-63.

Gustman, A.-Steinmeier, T.(2004), "The social security retirement earnings test, retirement and benefit claiming", NBER WP 10905.

Haider, S.- Lochran, D.(2008), "The effect of the social security earnings test on male labor supply: new evidence from survey and administrative data", Journal of Human Resources XLIII, 57-87. 
Hausman, J. (1985), “Taxes and labor supply”, chapter 4, Handbook of public economics, vol I., ed. A.Auerbach- M.Feldstein, .

Heim, B.- Meyer, B. (2003), "Structural labor supply models when budget constraints are nonlinear", Econometric Society 2004 North American Winter Meetings 567, Econmetric Society.

Honig,M.-Reimers, C.(1989), "Is it worth eliminating the retirement test?, Current Issues in social security", AEA Papers and proceedings, vol 79(2), 103-107.

Kuismanen,M.(2009), "Piece-wise or differentiable budget constraint? Estimating labour supply function for Finnish females", Applied economics 41, 1461-1472.

Moffit, R.(1986), "The econometrics of piecewise-linear budget constraints: a survey and exposition of the maximum likelihood method", Journal of business \&economic statistics, 4(3), 317-328.

Moffitt, R.-Nicholson(1982), “The effect of unemployment insurance on unemployment: the case of federal supplemental benefits", The review of economics and statistics, 1-11.

Song, J-Manchester,J.(2007), "New evidence on earnings and benefit claims following changes in the retirement earnings test in 2000", Journal of public Economics 91(3-4), 669-700 .

Van Soest, A. - Michaud, P.C.(2007), "How Did the Elimination of the Earnings Test above the Normal Retirement Age AffectRetirement Expectations “ , Fiscal Studies, 29(2), 197231.

Van Soest,A.-Woittiez,I.-Kapteyn,A.(1990), "Labor supply, income taxes and hours restrictions in the Netherlands", The Journal of human resources, 25(3), 517-558.

Zabalza, A.-Pissarides, C.-Barton, M.(1980), Social security and the choice between full-time work, part-time work and retirement, Journal of Public economics, 14, 245-276. 